\title{
Effect of Natural Fiber Reinforced Polypropylene Composite Using Resin Impregnation
}

\author{
Gibeop Nam, Nanqi Wu, Kazuya Okubo, Toru Fujii \\ Department of Mechanical Engineering, Doshisha University, Kyotanabe, Japan \\ Email: eum1502@mail4.doshisha.ac.jp
}

Received 15 October 2014; revised 10 November 2014; accepted 26 November 2014

Copyright $@ 2014$ by authors and Scientific Research Publishing Inc.

This work is licensed under the Creative Commons Attribution International License (CC BY). http://creativecommons.org/licenses/by/4.0/

(c) (i) Open Access

\begin{abstract}
In this paper, we deals with mechanical performance of resin impregnation with natural fiber and fiber reinforced composites. The effect of the addition of a rein impregnation process on static strength of the injection molded composites was investigated by carrying out tensile and banding tests, followed by Scanning electron microscopy (SEM) observation of fiber surface and fracture surface of composites. The tensile strength of natural fiber and natural fiber reinforced composites with resin impregnation method increases with Polyvinyl alcohol (PVA) impregnation. In addition, Phenol resin impregnation recovers fiber tensile strength after alkali treatment. Resin impregnation causes decrease in contact surface area; however, it does not cause decrease in mechanical properties. Our results suggest that the using rein impregnation method has better effect on the mechanical properties of natural fiber reinforced Polypropylene (PP) composites.
\end{abstract}

\section{Keywords}

Kenaf Fiber, Bamboo Fiber, Natural Fiber Reinforced Composite, Resin Impregnation Method, Polyvinyl Alcohol, Phenolic Resin, Fiber Treatment, Mechanical Properties

\section{Introduction}

Green composites are alternatives for previously used petroleum base plastics. These plastics were one of the great inventions in human history. Production and use of these plastics may exist primarily due to their cheap cost. However, it has been known such synthetic plastics cause a high rate of $\mathrm{CO}_{2}$ emissions and require the use of fossil fuel for disposal therefore new, renewable materials must be found. Plant based resources are increasing being harnessed to produce materials that aimed at replacing fossil origin resources. Environmental and cost 
concerns are at the center of extensive research and currently being undertaken worldwide to develop new materials that would replace the fossil origin materials. Green composites can reduce $\mathrm{CO}_{2}$ emissions and be used as sustainable materials [1] [2]. Currently green composites are not used in common industrial material due to its lack of stability and durability for industrial level. This study carried out on green composites not only developed as new materials but also modified their character for industrial level use.

Kenaf is a seasonal fiber crop closely related to cotton and jute. Historically, kenaf has been used as a cordage crop to produce twine, rope and sackcloth. There are now various new applications for kenaf including paper products, building materials, absorbents and animal feeds [3]. Bamboo is an abundant natural resource in Asia and South America due to its fast growing nature. Bamboo has been traditionally used to construct various living facilities and tools. Bamboo poses a high strength to weight ratio, because its fibers are longitudinally aligned in its body [4]. Recently the use of thermoplastic resins has been increasing [5]. This is directly related to their ease of recycling and mass production [6]. However, thermoplastic resins having high viscosity liquid form or solid form are more difficult to permeate into reinforced materials. Consequently, this can cause void content problems, low adhesive strength and water absorption problems. One idea was to reinforce fiber by the liquid type resin then use the fiber for composites [7]. With fiber treatment, it will be possible to control damage, improve the composite and waterproof properties [8]. The natural plants fiber poses a tube for transpiration of water. This feature can be used with low viscosity liquid, enabling the liquid to be absorbed into the fiber. Therefore permeated fiber using low viscosity liquid resin will be easier to work with a micro sized composite than permeated fiber using a different composite. It can be lighter than a matrix particle and fiber already filled up with resin will decrease water absorption [9] [10]. This method does not require high cost equipment or complex process. In the study, we will attempt to use resin impregnation as the treatment. Alkali treatment and resin impregnation were also used. Kenaf and bamboo bundle fibers were tested with these methods of treatment as well as fiber reinforced composites.

\section{Experiments}

\subsection{Materials}

The thermoplastic polymer PP, used as matrix material, was supplied by the Primepolymer (Japan). It had specific gravity of $0.90-0.91$, melting temperatures of $165^{\circ} \mathrm{C}-171^{\circ} \mathrm{C}$ and crystallinity of $82 \%$. Kenaf fiber was treated by alkali solution which $3 \mathrm{wt} \%$ of $\mathrm{NaOH}$ solution during 2 hours at room temperature. Raw bamboo fiber obtained from bamboo which boiled with alkali solution, so bamboo fiber did not additional alkali treatement. Fibers were washed with fluid water to remove impurities, such as; dust, fiber powder and $\mathrm{NaOH}$ on fiber surface. Then it was dried with fan over 2 days.

\subsection{Resin Impregnation Method}

In this study two kinds of materials were used for resin impregnation method. Polyvinyl alcohol (PVA) impregnation method was used on PVA produced by NACALAI TESQUE.INC (Japan). PVA solution was made with stirrer and $80^{\circ} \mathrm{C}$ water based $3 \%$ solution mixed over 24 hour period. It was to immerse natural fibers for two hours at room temperature. The Phenol resin treatment uses a 9\% ethanol based solution. The component of the mix has used a homogenizer for 15 minutes. It was to immerse natural fibers for two hours at room temperature. Raw kenaf fiber (UK), Alkali treatment kenaf fiber (NK), phenol resin impregnated kenaf fiber (PHK), PVA impregnated kenaf fiber (PVK) Raw bamboo fiber (UB), phenol resin impregnated bamboo fiber (PHB), PVA impregnated bamboo fiber (PVB) were used for testing and manufacturing. Resin impregnated fiber was dried with fan over 2 days.

\subsection{Fabrication of Composites and Test Specimens}

The composite specimens were prepared by using an injection molding machine. Before using injection molding machine, fiber and matrix were mixed in twin extruder twice. This happens inside the blocks which are heated at $170^{\circ} \mathrm{C}$. Both materials are added to the machine at the same time with a weight ratio of 3:10 (natural fiber: PP). The mold used to produce specimens are prepared according to the Japanese Industrial Standard, specifically the JIS K 7139 standard. The tensile, flexural and water absorption tests were conducted [11] [12]. For each test and type of composites were tested and the average values are reported. For tensile and bending tests, 15 and 10 spe- 
cimens were used for each test and were conducted with a cross head speed of $2 \mathrm{~mm} / \mathrm{min}$ at the average room temperature of $25^{\circ} \mathrm{C}$. Water absorption test used 5 specimens for each case and it followed the standard of room temperature. Before the test, specimens were dried in the oven at $70^{\circ} \mathrm{C}$ for 24 hours. After the dehydration, specimens were sodden into the water. Total of 4 times $(0.5,4,24,48$ hours after), sodden specimens were taken out from water and measure weight of specimens. Before they were put on scale, specimens were cleaned by paper towels.

\section{Results and Discussion}

\subsection{Bundle Fiber Morphology}

Scanning electron microscopy (SEM) provides an excellent examination of the surface morphology of untreated and treated kenaf fibers. It is expected that the surface morphology of untreated fiber will be different to that of treated fiber particularly in terms of their level of smoothness and roughness. Therefore studies of the fiber surface topography could provide vital information on the level of interfacial adhesion that would exist between the fiber and the matrix, when used as reinforcement fiber with and without treatment. All micrographs in this work are taken with 1000 times (1000×) magnification. Figure 1 shows the SEM micrograph of an untreated kenaf fiber. Clearly, UK and NK have fiber column consists of many vascular bundles and xylem. Yet, PVA and PHK fiber cases were filled up capillary tube with thermosetting resin. After resin impregnation, weight of fiber was increased. In Table 1, the main characteristics of the resin are reported as specified by the manufacturer.

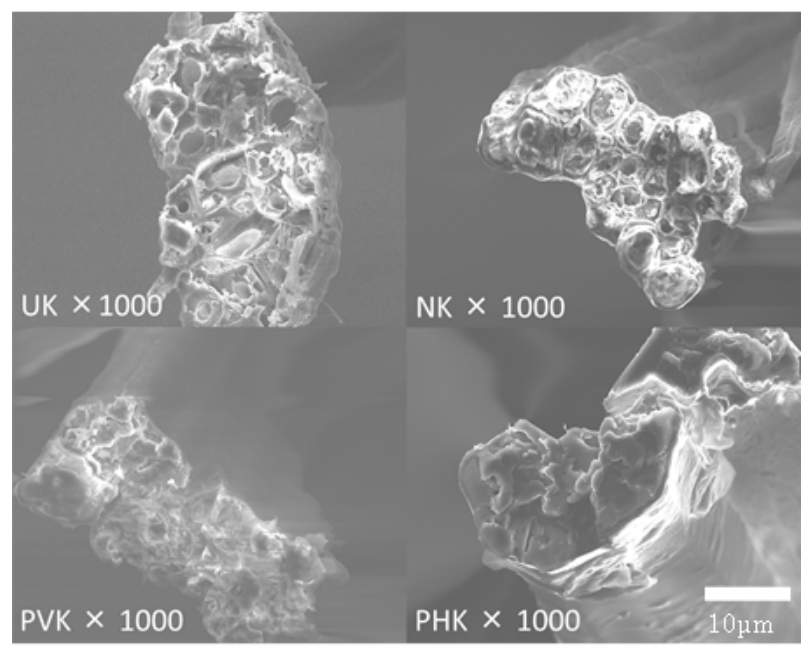

Figure 1. Surface morphology of treated kenaf fibers.

Table 1. Effect of natural fiber reinforced polypropylene composite using resin impregnation.

\begin{tabular}{cccc}
\hline & $\begin{array}{c}\text { Bundle Fiber Tensile } \\
\text { Strength (MPa) }\end{array}$ & $\begin{array}{c}\text { Composite Tensile } \\
\text { Strength (MPa) }\end{array}$ & $\begin{array}{c}\text { Composite Flexural } \\
\text { Strength (MPa) }\end{array}$ \\
\hline Untreated Kenaf (UK) & 638.43141 & 23.19745 & 40.29354 \\
Alkali Treated Kenaf (NK) & 603.66054 & 22.9729 & 39.74889 \\
PVA Impregnated Kenar (PVK) & 665.65501 & 25.15449 & 37.18552 \\
Phenolic Resin Impregnated Kenaf (PHK) & 710.33352 & 21.99716 & 36.66208 \\
Untreated Bamboo (UB) & 533.8595 & 19.73938 & 39.05965 \\
PVA Impregnated Bamboo (PVB) & 601.5478 & 19.49548 & 36.36777 \\
\hline
\end{tabular}




\subsection{Bundle Fiber Tensile Test}

Fiber bundle tensile strength of differently treated kenaf fiber bundles has been measured and the results are shown in Figure 2. The average unit break for every set of treatment, which represents the bundle fiber tensile strength, was summarized in Figure 2. From the figure, the average unit break of the bundle of PHK fiber and PVK fiber are higher than UK and NK. This is explained by the resin impregnation method that contributes to the increase in strength. However when alkali treated fiber, the fiber bundle tensile strength was decreased. An alkali treatment would certainly damage the fiber and consequently reduce the tensile strength of the fiber. Bamboo bundle fiber tensile strength trend also similar with kenaf. Resin impregnated fiber is higher than untreated and phenolic resin impregnated fiber has highest tensile strength. In this test, fiber diameter was measuredin 2D and supposed fiber shape iscylindrical. This caused a huge error in Figure 2. In this study, we checked over 50 specimens then it was conclude that the bundle fiber tensile strength was improved.

\subsection{Mechanical Testing for Composites}

The influence of fiber treatment on the tensile modulus and the tensile strength are illustrated in Figure 3 and Figure 4. In Figure 3, it can be seen that the tensile strength of the kenaf/PP composites increases with resin impregnation; whereas the strength of the kenaf/PP composite does not vary significantly with treatment. In contrast slightly PVA impregnation method case is higher than others. Bending test results shows PVA impregnation case is clearly $10 \%$ higher than others. It can be seen in Figure 3, the tensile strength of the bamboo/PP composites decreases with alkali treatment. This is because alkali solution was used when bamboo fiber was manufactured. So alkali treatment caused critical damage on fiber [9] [13]. Then resin impregnation method repaired fiber which is not enough to go over the untreated fiber reinforced composites.

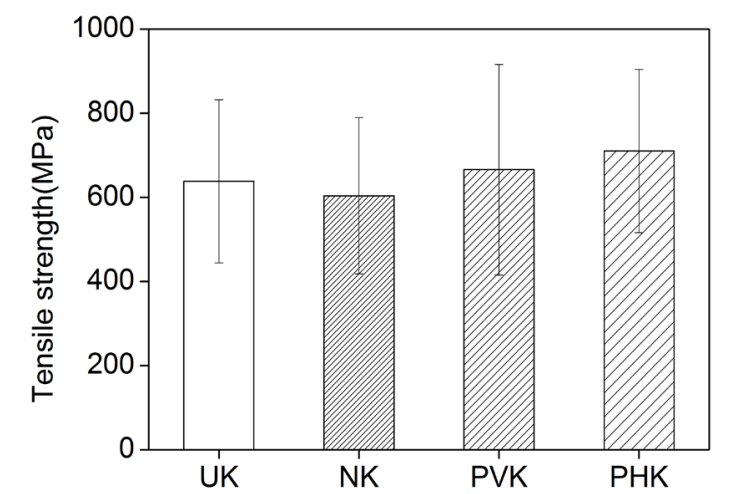

(a)

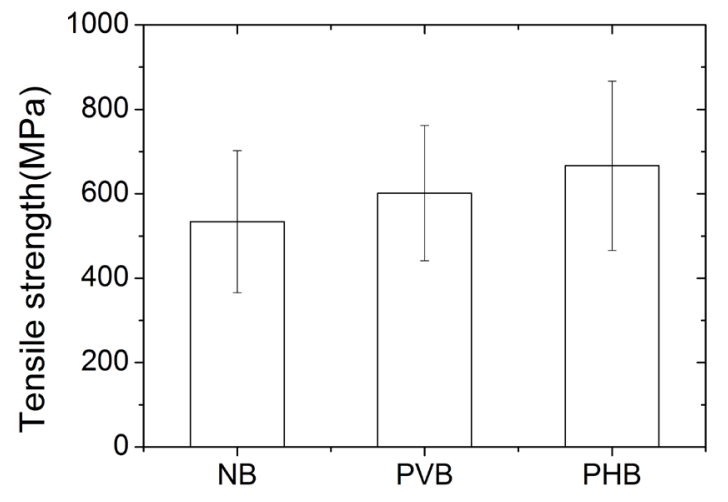

(b)

Figure 2. Resin impregnated bundle kenaf (a) bamboo (b) fiber tensile test.

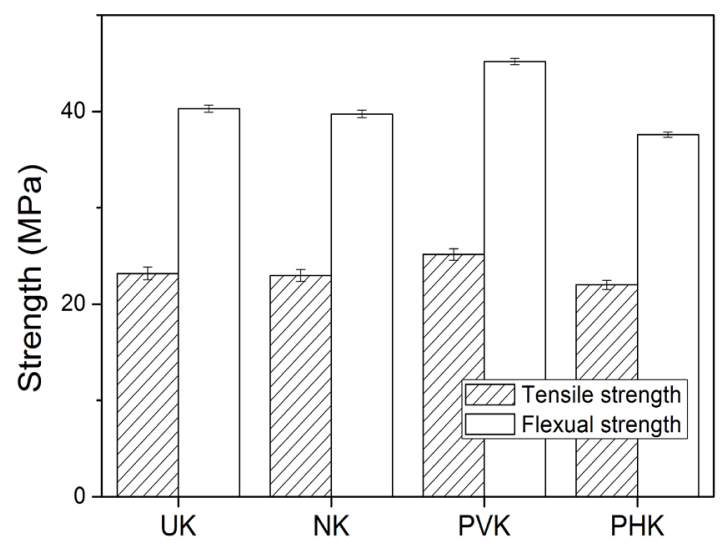

(a)

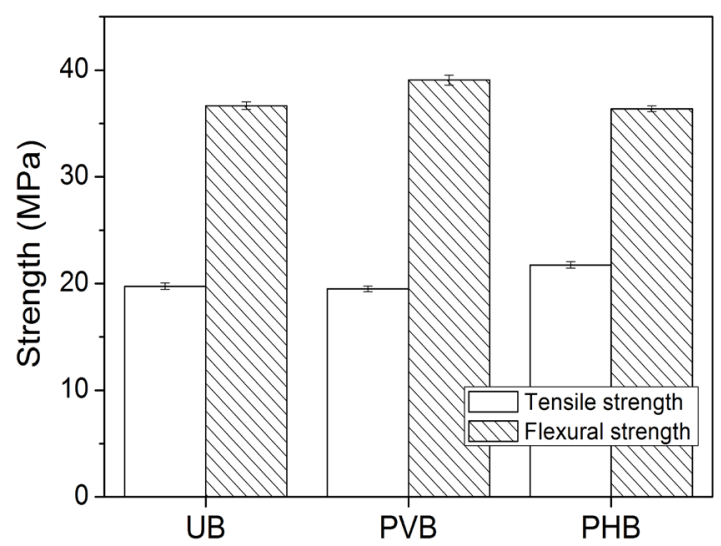

(b)

Figure 3. Mechanical properties of kenaf (a) and bamboo (b) PP composites. 


\subsection{Water Absorption}

Water absorption of composites relates to composite properties such as dimensional stability [14] [15]. The results of the water absorption tests are summarized below in Figure 5. It can be observed that the phenolic resin treated caused to decrease water absorption ratio but PVA treated caused the increase in absorption ratio. This is because PVA resin is one of hydrophilic material which can be caused due to link with water. These much lower values are obtained for composites than for fibers themselves, because cellulose fibers are covered by PP layers that slow down the diffusion of water.

\section{Conclusions}

In this study, resin impregnation was used as a reinforcement to improve the mechanical properties of natural fibers. Fiber and fiber reinforced composites were tested against fiber tensile tests, composite tensile tests and composite bending tests.

It was observed that resin impregnation fiber could increase tensile strength and flexural strength and elongation break of composites due to the fiber capillary tubes becoming filled. As for the kenaf fiber reinforced composites,

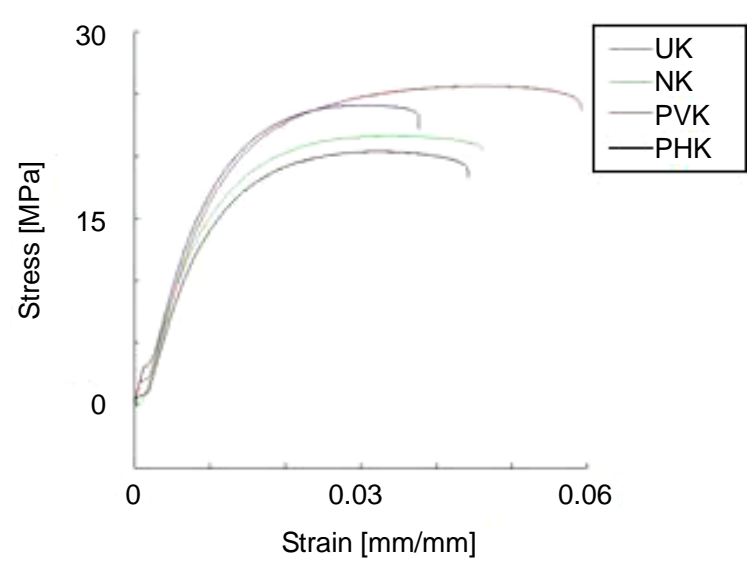

(a)

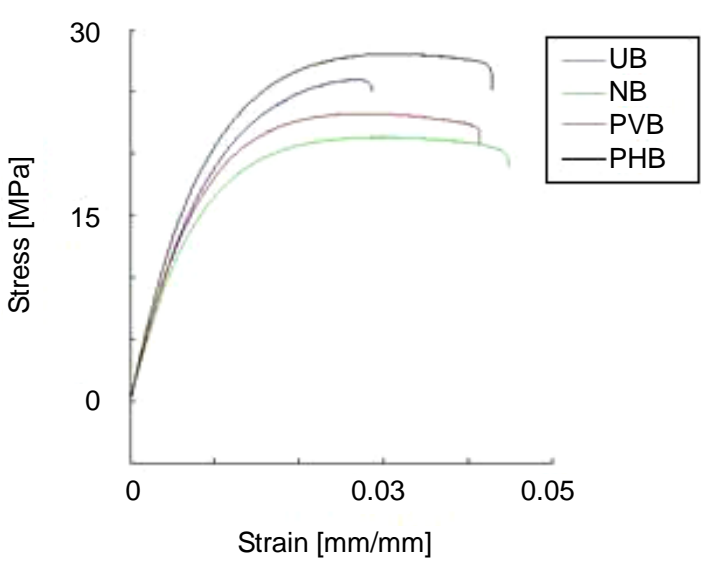

(b)

Figure 4. Stress-strain curve of natural fiber reinforced composites. (a) is kenaf and (b) is bamboo PP composite.

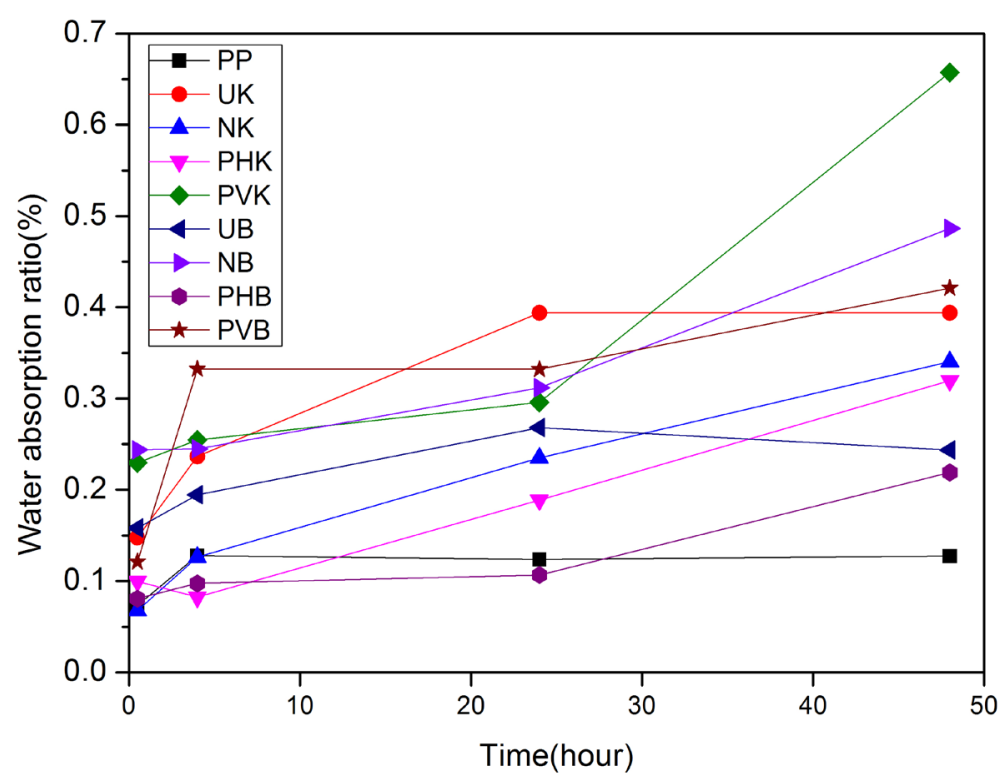

Figure 5. Water absorption test resin impregnated fiber with bamboo/PP and bamboo/MAPP/PP composites. 
the PVA impregnated kenaf fiber had a higher effect on mechanical properties than phenol resin impregnation. For the bamboo fiber reinforced composites, the phenol resin impregnated fiber had a higher effect on the mechanical properties than the PVA impregnation. It is also known that Alkali treatment can cause damage to the fiber. In conclusion resin impregnation can improve the mechanical properties of the natural fibers while alkali treatment should be excluded.

\section{Acknowledgements}

This study was supported by the High technological research project on "Research and Development Center for Advanced Composite Materials” of Ministry of Education, Culture, Sports, Science and Technology, Japan.

\section{References}

[1] Tokoro, R., Vu, D.M., Okubo, K., Tanaka, T., Fujii, T. and Fujiura, T. (2008) How to Improve Mechanical Properties of Polylactic Acid with Bamboo Fibers. Journal of Materials Science, 43, 775-787.

http://dx.doi.org/10.1007/s10853-007-1994-y

[2] Kalia, S., Kaith, B.S. and Kaur, I. (2009) Pretreatments of Natural Fibers and Their Application as Reinforcing Material in Polymer Composites-A Review. Polymer Engineering and Science, 49, 1253-1272. http://dx.doi.org/10.1002/pen.21328

[3] Mohd Edeerozey, A.M., Md Akil, H., Azhar, A.B. and Zainal Ariffin, M.I. (2007) Chemical Modification of Kenaf Fibers. Material Letters, 61, 2023-2025. http://dx.doi.org/10.1016/j.matlet.2006.08.006

[4] Okubo, K., Fujii, T. and Yamamoto, Y. (2004) Development of Bamboo-Based Polymer Composites and Their Mechanical Properties. Composite Part A, 35, 377-383. http://dx.doi.org/10.1016/j.compositesa.2003.09.017

[5] Ticoalu, A., Aravinthan, T. and Cardona, F. (2010) A Review of Current Development in Natural Fiber Composites for Structural and Infrastructure Applications. Proceedings of Southern Region Engineering Conference, Toowoomba, 1112 November 2010, 1-5.

[6] Parveen, S., Rana, S. and Fangueiro, R. (2012) Natural Fiber Composites for Structural Applications. International Conference on Mechanics of Nano, Micro and Macro Composite Structures.

[7] Mishra, S., Naik, J.B. and Patil, Y.P. (2000) The Compatibilising Effect of Maleic Anhydride on Swelling and Mechanical Properties of Plant-Fiber-Reinforced Novolac Composites. Composite Science and Technology, 60, 17291735. http://dx.doi.org/10.1016/S0266-3538(00)00056-7

[8] Kim, B.S., Chun, B.H., Lee, W.I. and Hwang, B.S. (2009) Effect of Plasma Treatment on the Wood Flour for Wood Flour/PP Composites. Journal of Thermoplastic Composites Materials, 22, 21-28. http://dx.doi.org/10.1177/0892705708091604

[9] Sain, M.M. and Kokta, B.V. (1993) Toughened Thermoplastic Composite. I. Cross-Linkable Phenol Formaldehyde and Epoxy Resins-Coated Cellulosic-Filled Polypropylene Composites. Journal of Applied Polymer Science, 48, 21812196.

[10] Mwaikambo, L. and Ansell, M. (2002) Chemical Modification of Hemp, Sisal, Jute, and Kapok Fibers by Alkalization. Journal of Applied Polymer Science, 84, 2222-2234. http://dx.doi.org/10.1002/app.10460

[11] Espert, A., Vilaplana, F. and Karlsson, S. (2004) Comparison of Water Absorption in Natural Cellulosic Fibres from Wood and One-Year Crops in Polypropylene Composites and Its Influence on Their Mechanical Properties. Composites Part A, 35, 1267-1276. http://dx.doi.org/10.1016/j.compositesa.2004.04.004

[12] Panthapulakkal, S. and Sain, M. (2007) Injection-Molded Short Hemp Fiber/Glass Fiber-Reinforced Polypropylene Hybrid Composites-Mechanical, Water Absorption and Thermal Properties. Journal of Applied Polymer Science, 103, 2432-2441. http://dx.doi.org/10.1002/app.25486

[13] Ichazo, M.N., Albano, C., Gonzalez, J., Perera, R. and Candal, M.V. (2001) Polypropylene/Wood Flour Composites: Treatments and Properties. Composite Structures, 54, 207-214. http://dx.doi.org/10.1016/S0263-8223(01)00089-7

[14] Khalil, H.P.S.A. and Ismail, H. (2001) Effect of Acetylation and Coupling Agent Treatments upon Biological Degradation of Plant Fibre Reinforced Polyester Composites. Polymer Testing, 20, 65-75. http://dx.doi.org/10.1016/S0142-9418(99)00080-X

[15] Hong, C.K., Hwang, I., Kim, N., Park, D.H., Hwang, B.S. and Nah, C. (2008) Mechanical Properties of Silanized Jute-Polypropylene Composites. Journal of Industrial and Engineering Chemistry, 14, 71-76. http://dx.doi.org/10.1016/j.jiec.2007.07.002 
Scientific Research Publishing (SCIRP) is one of the largest Open Access journal publishers. It is currently publishing more than 200 open access, online, peer-reviewed journals covering a wide range of academic disciplines. SCIRP serves the worldwide academic communities and contributes to the progress and application of science with its publication.

Other selected journals from SCIRP are listed as below. Submit your manuscript to us via either submit@scirp.org or Online Submission Portal.
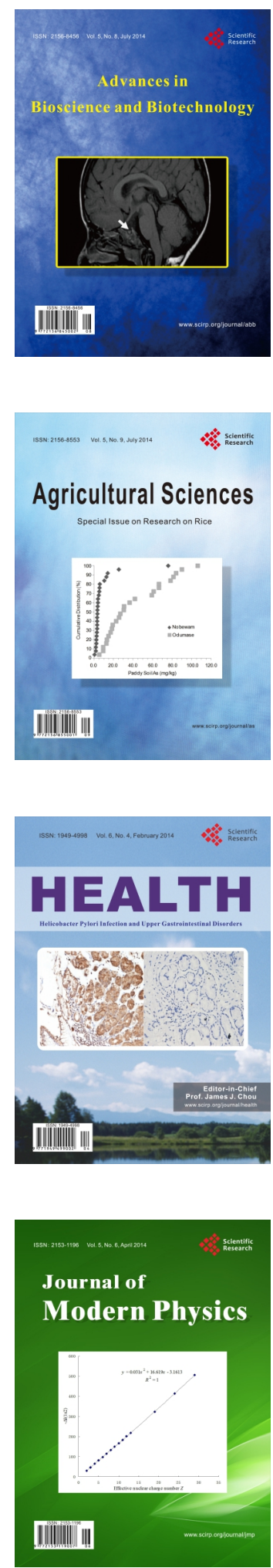
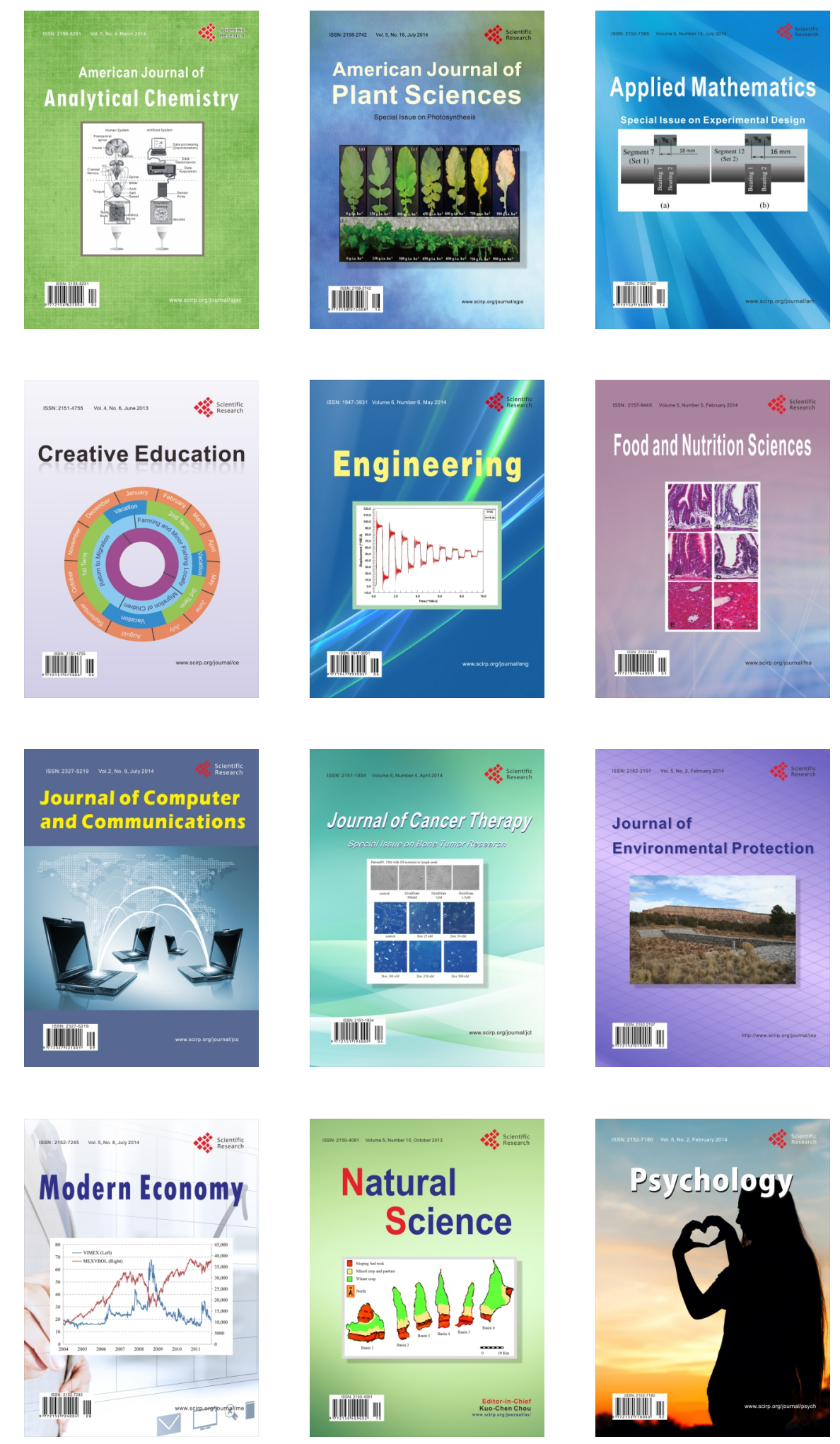